\title{
Calibration of model parameters for the cyclic response of end-plate beam-to-column steel-concrete composite joints
}

\author{
Pedro Nogueiro*
}

ISISE, Department of Applied Mechanics, Escola Superior de Tecnologia e Gestão, Polytechnic Institute of Bragança, Campus de Santa Apolónia, 5300 Bragança, Portugal (nogueiro@ipb.pt)

\section{Luís Simões da Silva}

ISISE, Department of Civil Engineering, University of Coimbra - Polo II Pinhal de Marrocos, 3030 Coimbra, Portugal (luisss@dec.uc.pt)

\section{Rita Bento}

Department of Civil Engineering, Instituto Superior Técnico Av. Rovisco Pais, Lisboa, Portugal (rbento@civil.ist.utl.pt)

\section{Rui Simões}

ISISE, Department of Civil Engineering, University of Coimbra - Polo II Pinhal de Marrocos, 3030 Coimbra, Portugal (rads@dec.uc.pt)

(Received November 2, 2007, Accepted January 16, 2009)

\begin{abstract}
Composite joints, considering the composite action of steel and concrete, exhibit, in general, high strength and high ductility. As a consequence, the use of this type of joint has been increasing in many countries, especially in those that are located in earthquake-prone regions. In this paper, a hysteretic model with pinching is presented that is able to reproduce the cyclic response of steel and composite joints. Secondly, the computer implementation and adaptation of the model in a spring element within the computer code Seismosoft is described. The model is subsequently calibrated using a series of experimental test results for composite joints subjected to cyclic loading. Finally, typical parameters for the various joint configurations are proposed.
\end{abstract}

Keywords : structural engineering; composite structures; buildings; component method; beam-to-column joints; dynamic behaviour; seismic behaviour; joint model.

\section{Introduction}

The global behaviour of a composite steel-concrete structure depends greatly on the composite

\footnotetext{
* Corresponding Author, Email: nogueiro@ipb.pt
} 
behaviour of the joints. Several studies have demonstrated that composite connections exhibit adequate mechanical properties, such as strength, ductility and energy dissipation capacity, for its use in structures located in seismic areas. The behaviour of usual composite joint typologies under cyclic loading, representative of the effects of a seismic event, is characterized by hysteretic loops with progressive degradation of strength and stiffness that eventually lead to failure of the joint. Typically, seismic events provoke relatively high amplitudes of rotation in the joint area, so that steel and concrete repeatedly reach the plastic range and the joint fails after a relatively small number of cycles. This typical behaviour is usually called oligocyclic fatigue, in close analogy with the behaviour of steel under repeated cyclic loading stressed into the plastic regime (Fig. 1a).

Predicting the behaviour of composite joints is quite complex, because it combines several phenomena such as material non-linearity (plasticity, strain-hardening, cracking of concrete), non-linear contact and slip, geometrical non-linearity (local instability), residual stress conditions and complicated geometrical configurations. Under cyclic loading, this behaviour is further complicated by successive static loading and unloading, as illustrated in Fig. 1b, where the characteristic pinching effect in the loading branches is clearly visible. For static monotonic situations it is nowadays possible to accurately predict the momentrotation response of a fairly wide range of joint configurations by applying the principles of the component method (Eurocode 4 - EN 1994-1-1, 2004; Simões da Silva et al. 2001). However, this is not the case for the cyclic situation. In this case, the usual approach is to develop multi-parameter mathematical expressions that are able to reproduce the range of hysteretic behaviours for a given group of composite joint typologies. Subsequently, the values of the parameters are calibrated to satisfactorily correlate to a range of section sizes for a given group of joint typologies.

Historically, two mathematical formulas have provided the basis for the majority of the models that have been proposed in the literature: Ramberg-Osgood type mathematical expressions (Ramberg and Osgood 1943), that usually express strain (generalized displacement) as a non-linear function of stress (generalized force) and Richard-Abbott type mathematical expressions (Richard and Abbott 1975), that usually relate generalized force (stress) to generalized displacement (strain).

Ramberg-Osgood based mathematical models were first used by Popov and Pinkey (1968) to model hysteresis loops of non-slip specimens and later applied to model the skew symmetric moment-rotation hysteretic behaviour of connections made by direct welding of flanges with or without connection plate (Popov and Bertero 1973). Mazzolani (1988) developed a comprehensive model based on the RambergOsgood expressions that was able to simulate the pinching effect, later modified by Simões et al. (2001) to allow for pinching to start in the unloading zone. It is noted that models based on the Ramberg-

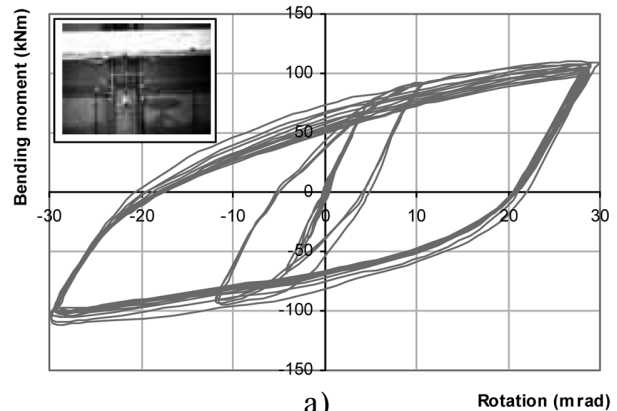

a)

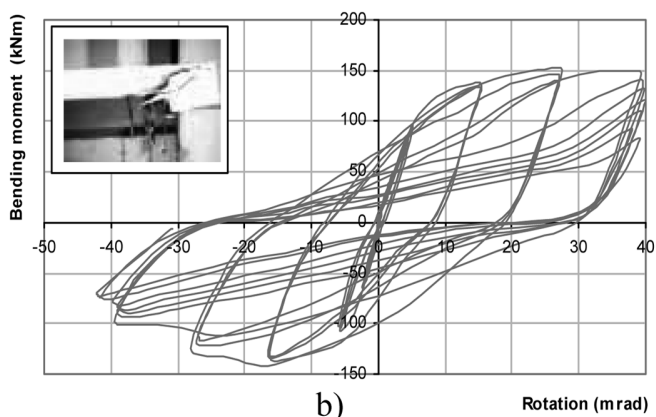

b)
Rotation (m rad)

Fig. 1 The hysteretic moment-rotation curve (Simões et al. 2001) without pinching (a) and with pinching (b). 
Osgood expressions present the disadvantage of expressing strain as a function of stress, which clearly complicates its integration in displacement-based finite element codes (that constitute the majority of the available applications) or the direct application for the calibration and evaluation of test results, almost always carried out under displacement-control once they reach the non-linear stage.

The Richard-Abbott expression was first applied to the cyclic behaviour of joints by De Martino et al. (1984). Unfortunately, that implementation was not able to simulate the pinching effect (Simões et al. 2001). Subsequently, Della Corte et al. (2000) proposed a new model, also based on the Richard-Abbott expressions, that was capable of overcoming this limitation and simulate the pinching effect, as well as strength and stiffness deterioration and the hardening effects.

Since the end of the 1980's, various research projects on the cyclic behaviour of steel-concrete composite joints were undertaken in several research centres, comprising a total number of 19 research projects and 72 individual experimental tests. These tests are summarized in Tables 1 to 3 and comprise various configurations, ranging from welded configurations to end-plate typologies. In general, the objective of these cyclic tests was the study of the seismic performance of the joints, following the observation of failures resulting from the Kobe and the Northridge seismic events.

Previous work by the authors (Nogueiro et al. 2007) was developed with the objective of applying and calibrating the model developed by Della Corte et al. (2000), based on the Richard-Abbott mathematical

Table 1 Welded steel-concrete composite joints

\begin{tabular}{|c|c|c|c|c|c|}
\hline$\|$ column & Beam & & \multicolumn{3}{|c|}{$\begin{array}{l}\text { Total number of research projects: } 5 \\
\text { Total number of tests: } 18 \\
\text { Total number of different load histories: } 2\end{array}$} \\
\hline \multicolumn{2}{|l|}{ Authors (date) } & $\begin{array}{l}\mathrm{N}^{\mathrm{o}} \\
\text { of tests }\end{array}$ & $\begin{array}{c}\text { Joint } \\
\text { Characterization }\end{array}$ & $\begin{array}{c}\text { Load } \\
\text { History }\end{array}$ & $\begin{array}{l}\text { Main parameters } \\
\text { investigated }\end{array}$ \\
\hline $\begin{array}{l}\text { Sheikh et al. } \\
\text { (1989) }\end{array}$ & & 8 & $\begin{array}{l}\text { Steel beam which is continuous } \\
\text { through the joint was a hybrid built- } \\
\text { up section, with roughly } 40 \% \text { of the } \\
\text { shear strength of a rolled shape (W18 } \\
\times 76) \text { and similar moment capacity. } \\
\text { Column in concrete }(510 \times 510) \text {, designed } \\
\text { to exceed the connection strength. }\end{array}$ & (2) & $\begin{array}{l}\text { Evaluation of strength and stiff- } \\
\text { ness; confinement effect of stirrups } \\
\text { in the nodal zone. }\end{array}$ \\
\hline $\begin{array}{l}\text { Plumier and } \\
\text { Schleich (1993 }\end{array}$ & & 6 & $\begin{array}{l}\text { Three external joints and three inter- } \\
\text { nal joints, combining steel elements, } \\
\text { composite column and beam. } \\
\text { Beam in HEA } 260 \text { and columns in } \\
\text { HEB300. }\end{array}$ & (1) & $\begin{array}{l}\text { Contribution of the shear panel } \\
\text { in the energy dissipation. Study } \\
\text { the strength and rotation capac- } \\
\text { ity joint. }\end{array}$ \\
\hline $\begin{array}{c}\text { Pradhan and } \\
\text { Bouwkamp (199 }\end{array}$ & & - & $\begin{array}{l}\text { Fully welded joints. Beam section } \\
\text { HEA } 260 \text { and column section HEB300. } \\
\text { Some tests are with beam and col- } \\
\text { umn filled-in reinforced concrete. }\end{array}$ & - & $\begin{array}{l}\text { Column shear web panel zone, } \\
\text { shear panel thickness and contri- } \\
\text { bution of the concrete. }\end{array}$ \\
\hline $\begin{array}{c}\text { Bursi and } \\
\text { Ferrario }(2003)\end{array}$ & & 3 & $\begin{array}{l}\text { Steel concrete welded beam-to-col- } \\
\text { umn external joint. IPE330 and IPE400 } \\
\text { beam sizes and HEB360 column size }\end{array}$ & (1) & $\begin{array}{l}\text { Seismic performance of composite } \\
\text { beam. }\end{array}$ \\
\hline $\begin{array}{l}\text { Calado } \\
(2003)\end{array}$ & & 1 & $\begin{array}{l}\text { Welded steel composite beam (IPE300) } \\
\text { to column (HEB200) external joint. }\end{array}$ & (1) & $\begin{array}{l}\text { Cyclic behaviour, modes of fail- } \\
\text { ure and effect of the slab. }\end{array}$ \\
\hline
\end{tabular}


Table 2 Set angle steel-concrete composite joints

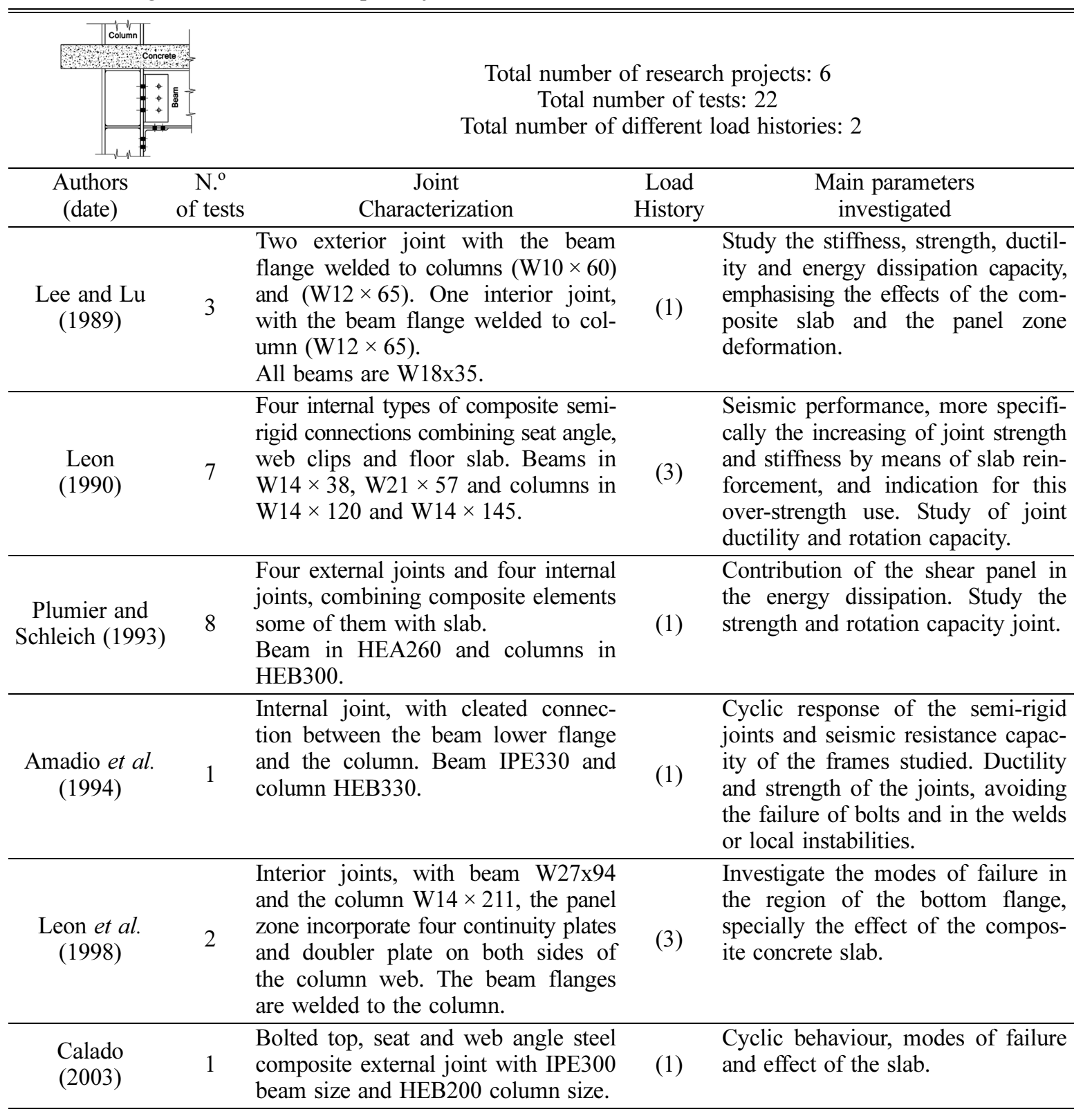

model, with a series of experimental test results for steel joints subjected to cyclic loading. In a previous work, Nogueiro et al. (2003) investigated the effect of pinching on the seismic response of steel frames and concluded that it leads to an increase of the joint rotation of about $20 \%$, thus increasing the ductility demand on the joints to avoid failure. Besides the brief presentation of a hysteretic model with pinching based on the Richard-Abbott mathematical model and developed by Della Corte et al. (2000), it is the objective of this paper: (i) to describe the computer implementation and adaptation of this model in a spring element within the computer code SeismoStruct (2007); (ii) to apply and calibrate the model 
Table 3 End-plate steel-concrete composite joints

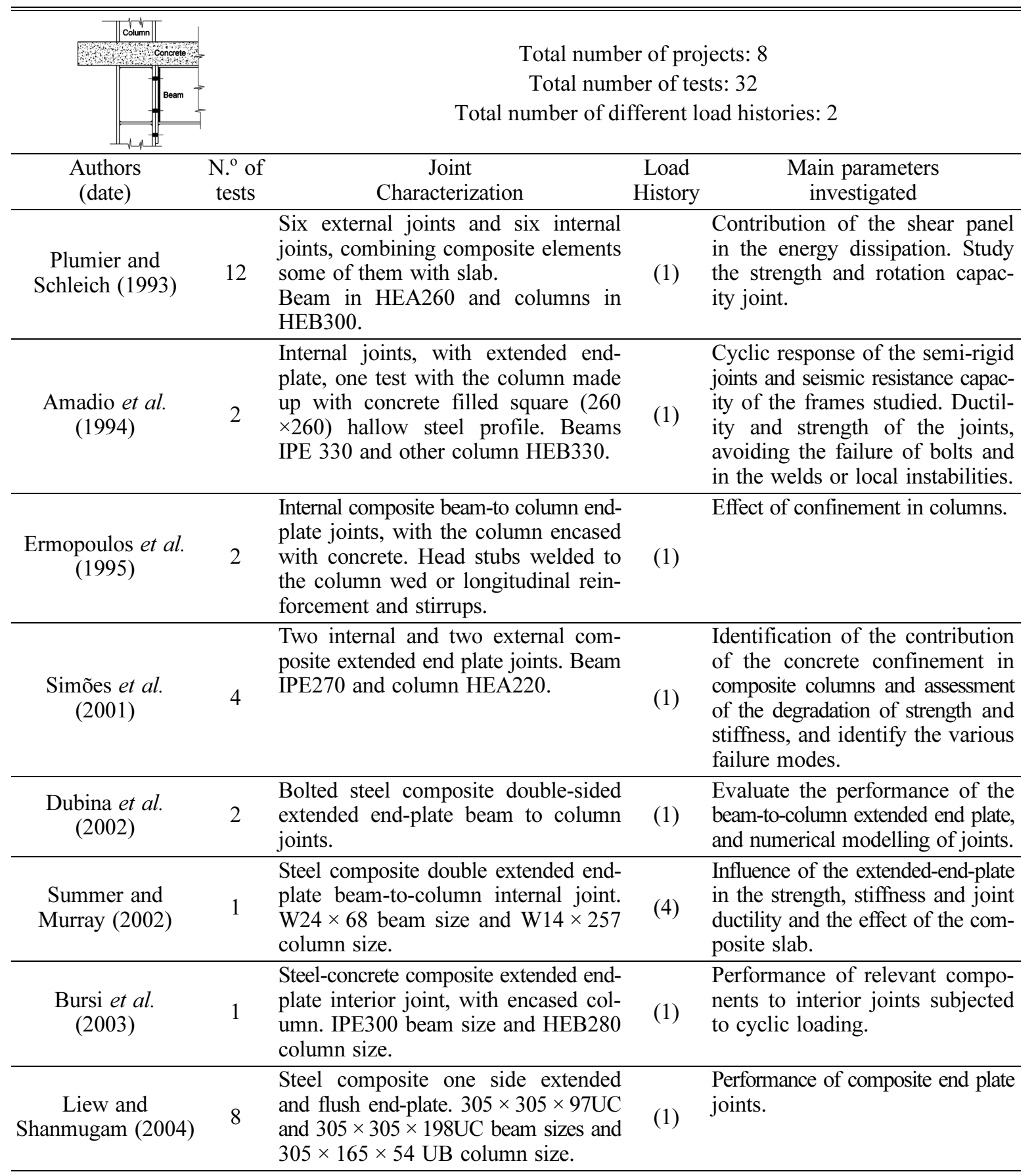

The cyclic loads histories recorded in these tests, four in total, are summarized in Table 4.

with a series of experimental test results for composite joints (described in Tables 1 to 3 ) subjected to cyclic loading; and (iii) to compare and propose typical parameters for the chosen joint configurations. 
Table 4 Cyclic load histories

\begin{tabular}{ccl}
\hline \hline Load History & N. $^{\circ}$ of tests & \multicolumn{1}{c}{ Description } \\
\hline$(1)$ & 54 & $\begin{array}{l}\text { ECCS procedure. } \\
\text { Two cycles to } 1 \% \text { distortion, two cycles to } 2 \% \text { distortion and one half-cycle to } \\
4 \% \text { distortion. }\end{array}$ \\
$(2)$ & 8 & $\begin{array}{l}\text { Full reversal cycles at } 0.1,0.25,0.50,0.75,1.0,1.5,2.0 \text { and 3.0\% interstorey } \\
\text { drifts. }\end{array}$ \\
(3) & 9 & SAC standard and SAC near-fault loading history.
\end{tabular}

\section{Modified Richard-Abbott model}

According to this model (Della Corte et al. 2000), the loading curve for a generic branch of the moment-rotation curve of a joint is given by the following equation:

$$
M=M_{n}-\frac{\left(k_{a}-k_{p a}\right) \cdot\left(\phi_{n}-\phi\right)}{\left[1+\left|\frac{\left(k_{a}-k_{p a}\right) \cdot\left(\phi_{n}-\phi\right)}{M_{0 a}}\right|^{N}\right]^{1 / N}}-k_{p a} \cdot\left(\phi_{n}-\phi\right)
$$

where $M_{0 a}=M_{n}+M_{0 p}$. The unloading curve is obtained in the same way, replacing $\left(M_{n}, \phi_{n}\right)$ by $\left(M_{p}, \phi_{p}\right)$ and the parameters $M_{0 a}, k_{a}$ and $k_{p a}$ by the corresponding values evaluated at unloading, $M_{0 d}, k_{d}$ and $k_{p d}$.

To describe the pinching phenomenon, two limit curves are introduced, that represent a lower and an upper bounds to possible $M-\phi$ values. Both curves have a Richard-Abbott type law, and are characterised by parameters $K_{o p}, M_{o p}, K_{h p}, n_{p}$ (lower bound curve) and $K_{o}, M_{o}, K_{h}, n$ (upper bound curve). Additionally, any generic point $(M, \phi)$ along the real path is also considered to belong to a Richard-Abbott type curve, where the relevant parameters are defined as follows:

$$
\begin{aligned}
& K_{o t}=K_{o p}+\left(K_{o}-K_{o p}\right) \times t \\
& M_{o t}=M_{o p}+\left(M_{o}-M_{o p}\right) \times t
\end{aligned}
$$

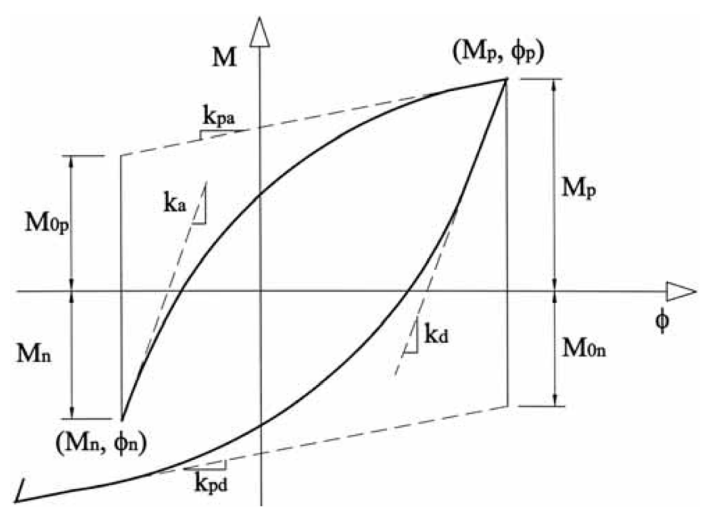

Fig. 2 Generic loading and unloading branches 


$$
\begin{gathered}
K_{h t}=K_{h p}+\left(K_{h}-K_{h p}\right) \times t \\
n_{t}=n_{p}+\left(n-n_{p}\right) \times t
\end{gathered}
$$

The parameter $t$, ranging in the interval [0,1], defines the transition law from the lower bound to the upper bound curve. It must reproduce, as closely as possible, the shape of the experimental curves and is given by:

$$
t=\left[\frac{\left(\phi / \phi_{\mathrm{lim}}\right)^{t_{1}}}{\left(\phi / \phi_{\mathrm{lim}}\right)^{t_{1}}+1}\right]^{t_{2}}
$$

where $t_{1}, t_{2}$ and $\phi_{\text {lim }}$ are three experimentally calibrated parameters. Fig. 3 illustrates, qualitatively, the resulting pinching behaviour with reference to one single excursion from the origin.

In case of a generic deformation history, the parameter $\phi_{\text {lim }}$ is related to the maximum experienced deformation in the direction of the loading branch to be described. It is evaluated according to the following relationship:

$$
\phi_{\lim }=C\left(\left|\phi_{o}\right|+\phi_{\max }\right)
$$

where $\left|\phi_{o}\right|$ is the absolute value of the deformation corresponding to the starting point of the current excursion, $\phi_{\max }$ is the maximum absolute value of the deformation experienced in the previous loading history, in the direction of loading branch to be described (Fig. 4a) and $C$ is a calibration parameter. The unloading branch is assumed to be linear with a slope equal to the initial stiffness $K_{o}$ up to the interception with the straight line obtained drawing a parallel to the hardening line going through the origin. This allows the Bauschinger effect to be considered.

Cyclic action in the inelastic range produces accumulation of plastic deformation, until ductility of the system is locally exhausted and failure occurs due to fracture. In some cases, the repetition of loading is accompanied by degradation of the structural response because of deterioration of its mechanical properties. This can be taken into consideration both for strength $\left(M_{o, \text { red }}\right)$ and stiffness $\left(K_{o, r e d}\right)$ using the following expressions:

$$
M_{o, \text { red }}=M_{o}\left(1-i_{M} \times \frac{E_{h}}{M_{y} \times \bar{\phi}_{u, o}}\right) \quad K_{o, \text { red }}=K_{o}\left(1-i_{K} \times \frac{E_{h}}{K_{o} \times \bar{\phi}_{u, o}}\right) .
$$

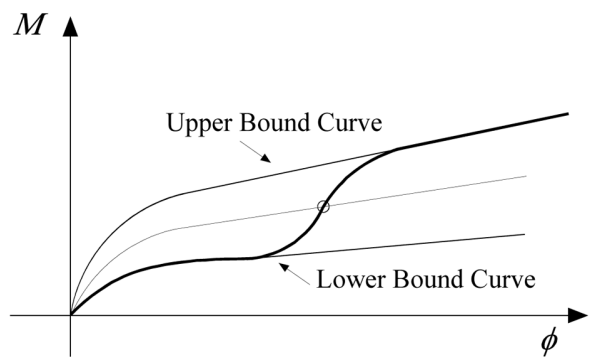

$$
M=\frac{\left(K_{o t}+K_{h t}\right) \times \phi}{\left[1+\left|\frac{\left(K_{o t}+K_{h t}\right) \times \phi}{M_{o t}}\right|^{n t}\right]^{\frac{1}{n t}}}+K_{h t} \times \phi
$$

Fig. 3 The loading branch with pinching 


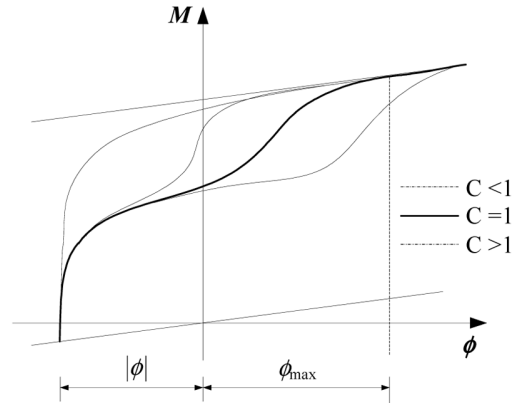

a)

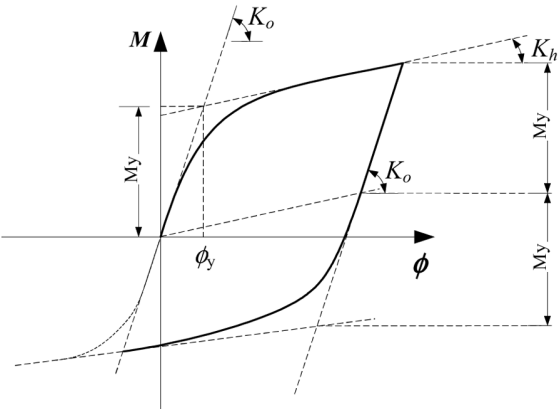

b)

Fig. 4 Effect of parameter $C$ (a) and definition of the unloading branch (b)

$\bar{\phi}_{u, o}$ is the corresponding ultimate value in the case of one single excursion from the origin (monotonic loading), $E_{h}$ is the hysteretic energy accumulated in all previous experienced excursions, $M_{y}$ represents the conventional yield resistance of the joint, $K_{o}$ the initial stiffness as defined in the Fig. $4 \mathrm{~b}$ and coefficient $i$ is an empirical parameter related to damage rate.

Hardening due to cyclic plastic deformation is considered to be isotropic. Besides, experimental results of constant deformation amplitude tests for joints not exhibiting strength deterioration show that cyclic hardening grows up in few cycles and then becomes stable.

Therefore, the following assumption is made:

$$
\begin{array}{ll}
M_{o, \text { inc }}=M_{\mathrm{o}} & \text { if } \phi_{\max } \leq \phi_{y} \\
M_{o, \text { inc }}=M_{o}\left(1+H_{h} \times \frac{\phi_{\max }-\phi_{y}}{\phi_{y}}\right) & \text { if } \phi_{\max } \geq \phi_{y}
\end{array}
$$

$M_{o}$ and $M_{o, i n c}$ are the initial and increased value of strength, respectively; $\phi_{\max }$ is the maximum value of deformation reached in the loading history (in either positive or negative direction); $\phi_{y}$ is the conventional yielding value of deformation (see Fig. $4 \mathrm{~b}$ ); $H_{h}$ is an empirical coefficient defining the level of the isotropic hardening (Filippou et al. 1983). The above formulation practically corresponds to translate the asymptotic line of the original Richard-Abbott equation (De Martino et al. 1984), as a function of the extent of the plastic deformation.

\section{Computational Implementation}

The numerical implementation of the hysteretic model described above was carried out using the Delphi (Delphi 7, 2002) development platform. A six degree-of-freedom spring element was implemented in the structural analysis software SeismoStruct (2007). The implementation comprised two major parts. The first consists of the management of the hysteretic cycles, where a clear distinction between positive and negative moment must be made because of possible asymmetry of joint response under hogging or sagging bending. An illustrative flowchart of the cycle management is shown in Fig. 5.

The second part of the implementation relates to the development of the code for each cycle. Several 


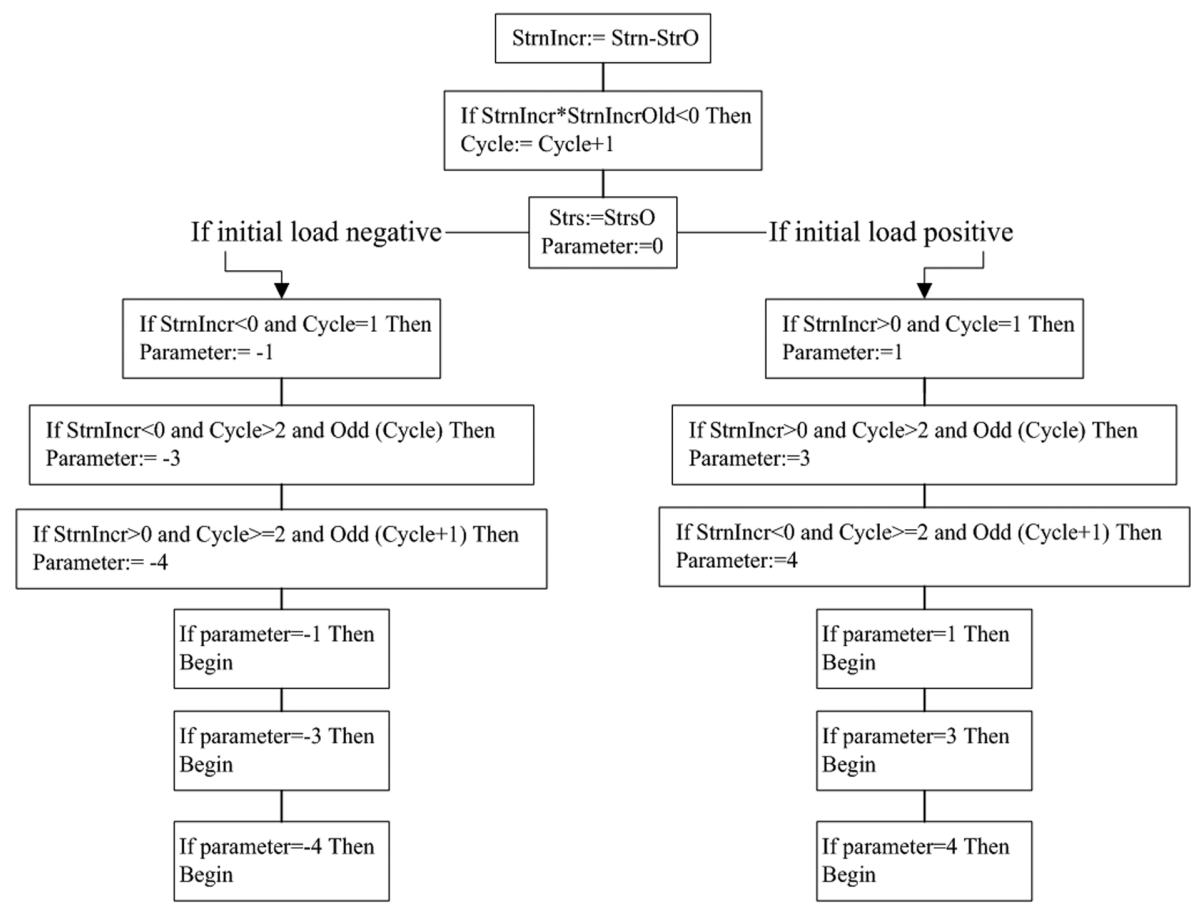

Fig. 5 Flowchart for the management of hysteretic cycles

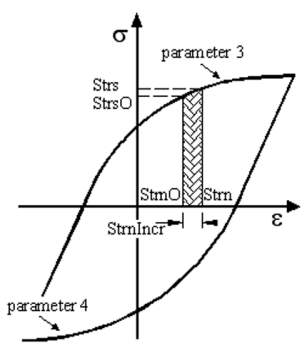

a)

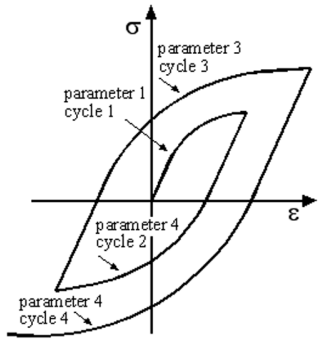

b)

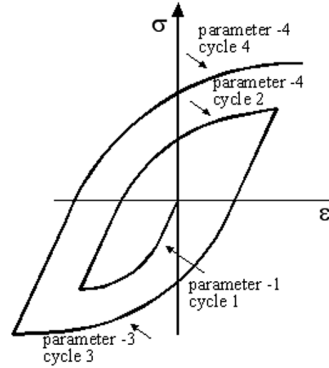

c)

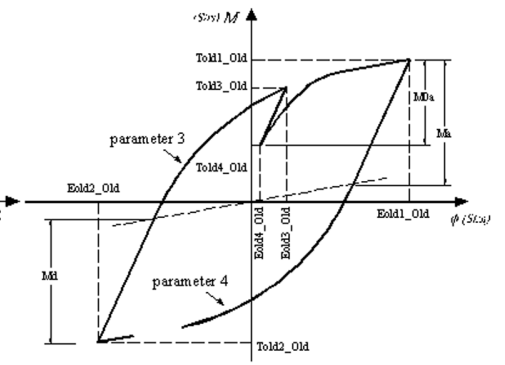

d)

Fig. 6 a) Definition of the increment; b) Hysteretic curve for positive starting; c) Hysteretic curve for negative starting; d) Small loading for odd parameters

possibilities must be considered, depending on the starting bending moment (positive or negative) and the sign of the strain increment (positive or negative), as can be seen in the Figs. $6 \mathrm{a}, \mathrm{b}$ and c.

In total, 30 parameters have to be defined for this model, fifteen for the ascending branches (subscript $a$ ) and fifteen for the descending branches (subscript $d$ ): $K_{a}$ (and $K_{d}$ ) is the initial stiffness, $M_{a}$ (and $M_{d}$ ) is the strength, $K_{p a}$ (and $K_{p d}$ ) is the post limit stiffness, $n_{a}$ (and $n_{d}$ ) is the shape parameter, all these for the upper bound curve (see Fig. 1), $K_{a p}$ (and $K_{d p}$ ) is the initial stiffness, $M_{a p}$ (and $M_{d p}$ ) is the strength, $K_{\text {pap }}$ (and $K_{p d p}$ ) is the post limit stiffness, $n_{a p}$ (and $n_{d p}$ ) is the shape parameter, all these for the lower bound curve, $t_{1 a}$ and $t_{2 a}$ (and $t_{1 d}$ and $t_{2 d}$ ) are the two parameters related to the pinching, $C_{a}$ (and $\mathrm{C}_{d}$ ) is the calibration parameter related to the pinching, normally equal to 1 (see Fig. $4 \mathrm{a}$ ), $i_{K a}$ (and $i_{K d}$ ) is the 
calibration coefficient related to the stiffness damage rate, $i_{M a}$ (and $i_{M d}$ ) is the calibration coefficient related to the strength damage rate, $H_{a}$ (and $H_{d}$ ) is the calibration coefficient that defines the level of isotropic hardening and $E_{\text {maxa }}$ (and $E_{\text {maxd }}$ ) is the maximum value of deformation.

The model must deal with all kinds of loads, especially those resulting from seismic action where the loading and unloading branches can be either large or small. In particular, the model must be prepared to consider an inversion of loading as shown in Fig. 6d) for both the positive and the negative starting points. The versatility of the model may be confirmed elsewhere (Nogueiro et al. 2007).

\section{Application to composite joints}

\subsection{Description of the experimental tests}

In order to establish reliable parameters for a range of end-plate beam-to-column composite joint configurations and to validate the accuracy of the model, a group of well-documented experimental results was selected from the literature. These tests were performed by Simões et al. (2001), Dubina et al. (2002) and Liew et al. (2004) and are summarized in Table 5.

Tests 1 and 2 correspond to external joints. All other tests correspond to internal joints. Tests 2 and 4 have the column encased in concrete. Tests 1 to 4 have $12 \mathrm{~mm}$ thick end-plates and M20 bolts, grade 8.8 and the steel is grade S235. For tests 5 to 9 the steel is grade S275. Tests 5, 6 and 7 have M20 preloaded bolts, grade 10.9 and the end-plate is double extended and $20 \mathrm{~mm}$ thick. All cyclic tests for internal nodes are loaded in phase, except for test 7 . Test 8 has the column web stiffened with a doubler plate (Fig. 9d) and a flush end-plate connection. Test 9 corresponds to an extended end plate connection. For tests 8 and 9 the end-plate is $12 \mathrm{~mm}$ thick and the bolts are M20, Grade 10.9. All concrete slabs have $12 \mathrm{~cm}$ thickness and continuous steel reinforcement around the column. Figs. 7 to 9 illustrate the joint details.

\subsection{Application of the modified Richard-Abbot model}

\subsubsection{Introduction}

The application of the model should be carried out in two consecutive steps. Firstly, the initial

Table 5 Experimental tests

\begin{tabular}{|c|c|c|c|c|c|c|c|c|c|c|}
\hline $\mathrm{N}^{\mathrm{o}}$ & Test Ref. & Author & Type & Beam & Coll & $\begin{array}{c}\mathrm{h}_{\mathrm{c}} \\
\mathrm{cm}\end{array}$ & $\begin{array}{c}\mathrm{M}_{\mathrm{y}}^{+} \\
\mathrm{KNm}\end{array}$ & $\begin{array}{c}\mathrm{M}_{\mathrm{y}}^{-} \\
\mathrm{KNm}\end{array}$ & $\begin{array}{c}\mathrm{K}_{\mathrm{y}}^{+} \\
\mathrm{KNm} / \mathrm{rad}\end{array}$ & $\begin{array}{c}\mathrm{K}_{\mathrm{y}}^{-} \\
\mathrm{KNm} / \mathrm{rad}\end{array}$ \\
\hline 1 & E9 & Simões & Exter & 8 & HEA220 & 12 & 114 & 115 & 24570 & 26810 \\
\hline 2 & E10 & Simões & Extern & IPE270 & $\overline{0+\mathrm{C}}$ & 12 & 170 & 159 & 36950 & 40830 \\
\hline 3 & E11 & Simões & Internal & IPE270 & HEA220 & 12 & 83 & 81 & 16500 & 18830 \\
\hline 4 & E12 & Simões & Internal & IPE270 & HEA220+C & 12 & 117 & 118 & 34440 & 36220 \\
\hline 5 & BX-CUC1 & Dubina & Internal & IPE270 & HEA220 & 12 & 143 & 137 & 36870 & 37920 \\
\hline 0 & BX-CUC2 & Dubina & Internal & IPE270 & HEA220 & 12 & 143 & 137 & 36870 & 37920 \\
\hline 7 & $\mathrm{BX}-\mathrm{CSC} 1 * *$ & Dubina & Internal & IPE270 & HEA220 & 12 & 195 & 150 & 102500 & 75050 \\
\hline 8 & $\mathrm{CJ} 2$ & Liew & Internal & $305 \times 305 \times$ UB50 & $305 \times 305 \times 97 \mathrm{UC}$ & 12 & $165^{*}$ & $150^{*}$ & 27648 & 16987 \\
\hline 9 & CJ4 & Liew & Internal & $305 \times 305 \times \mathrm{UB} 50$ & $5 \times 305 \times 97 \mathrm{UC}+\mathrm{S}$ & 12 & $190^{*}$ & $165^{*}$ & 42697 & 45118 \\
\hline
\end{tabular}

HEA220 + C (concrete); $305 \times 305 \times 97 \mathrm{UC}+\mathrm{S}$ (Stiffening of column wed). *Estimated value. ${ }^{* *}$ Symmetrical test




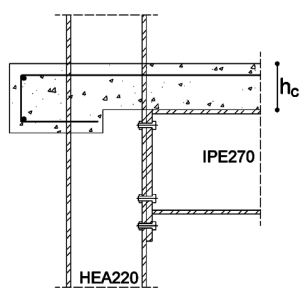

a)

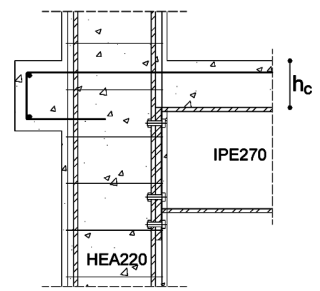

b)

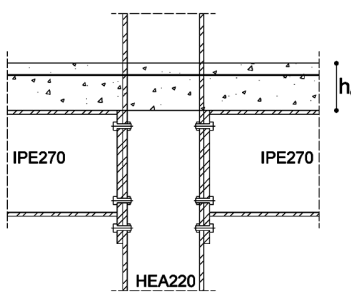

c)

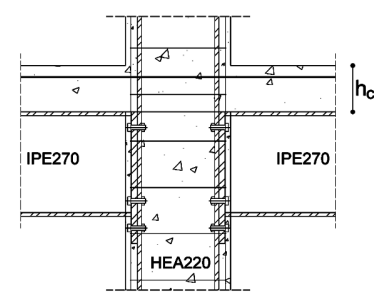

d)

Fig. 7 Joints 1 (a), 2 (b), 3 (c) and 4 (d)

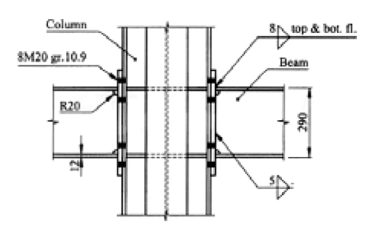

a)

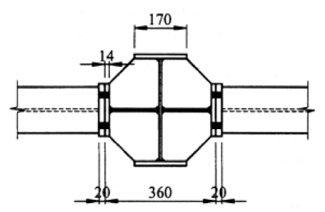

b)

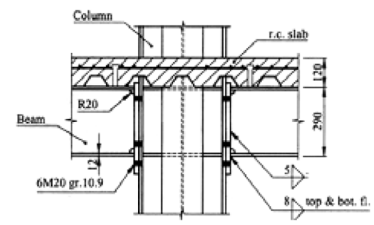

c)

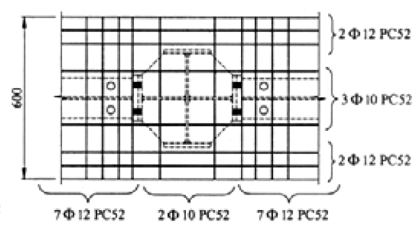

d)

Fig. 8 Bare steel joint 5 and $6(a, b)$ and composite joint 7 (c, d)

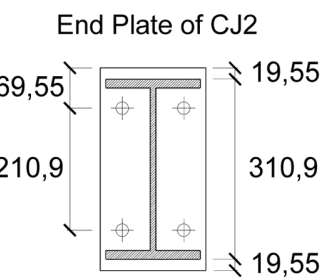

a)

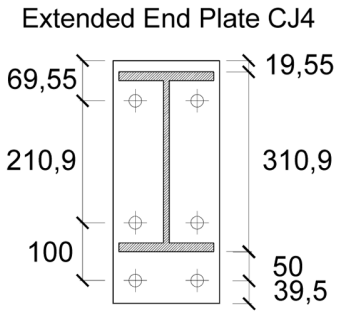

b)

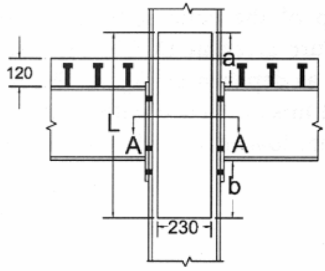

c)

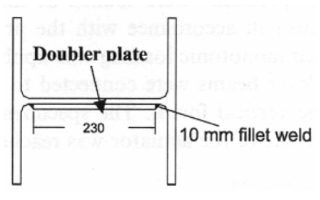

d)

Fig. 9 End plate for joints 8 (a) and 9 (b), composite joint 9 (c) and web stiffener (d)

stiffness, moment resistance and post-limit stiffness should be obtained from static monotonic tests. This was the case for all tests except for tests 8 and 9. Subsequently, the cyclic tests allow the calibration of the remaining parameters such as strength and stiffness deterioration coefficients, the isotropic hardening and the pinching parameters. The following sub-sections illustrate the application of the model to the selected tests.

\subsubsection{End-plate joints 1 to 4}

The cyclic loading strategy applied to joints 1 to 4 is illustrated in Fig. 10. For the external node joints 1 and 2 and for the cycles with the largest amplitude, it led to maxima total joint rotations of about 40 mrad, thus matching the Eurocode 8 ductility requirements (EN 1998-1, 2004) for dissipative joints. For joints 3 and 4 (internal node with symmetrical loading), the maxima total joint rotations reached about 25 30 mrad, below the requirements of Eurocode 8. However, these joints did not fail, the reduced rotations resulting from limitations in the loading equipment (Simões et al. 2001). 


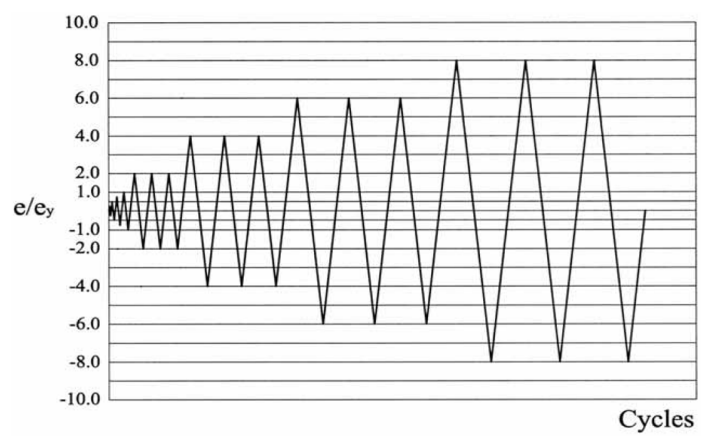

Fig. 10 Cyclic loading strategy for joints 1 to 4
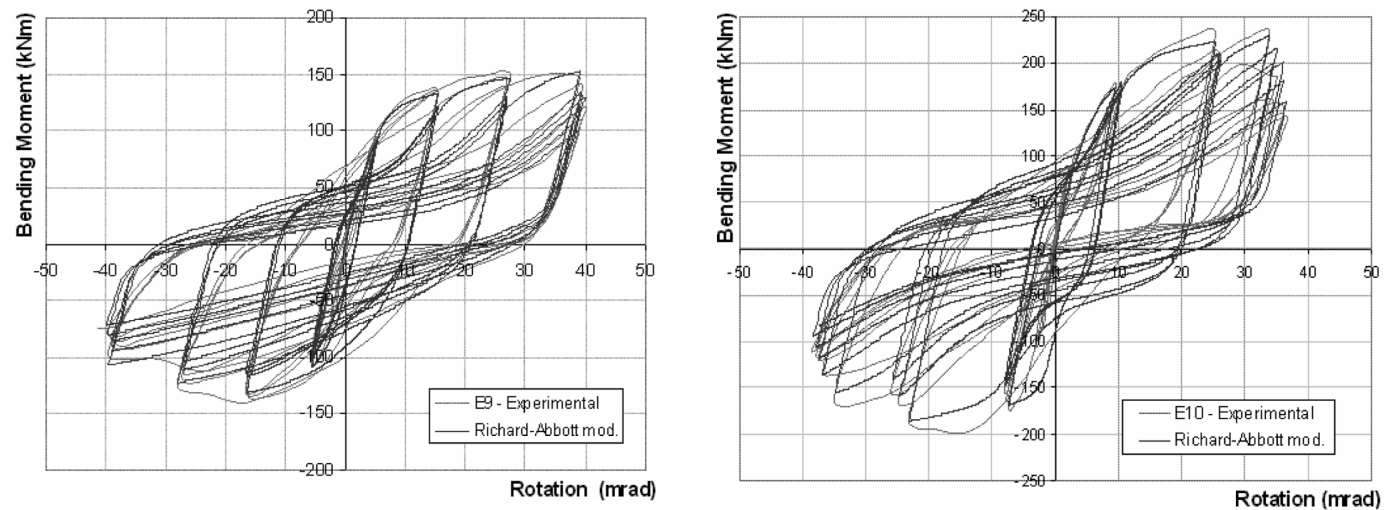

Fig. 11 Hysteretic curves for joints 1 and 2

For test 1 (test reference E9) a strong degradation of its mechanical properties (Fig. 11) due to bending of the end-plate and the column flange in the tension zone at the bottom level of the beam and the crushing of the concrete in compression at the interface between the slab and the column flange can be observed.

The contribution of the column web panel distortion to the total joint rotation in test 2 (E10) is not so obvious, when compared to the test $\mathrm{E} 9$, due to the additional resistance provided by the encasing concrete.

Fig. 11 shows the results obtained using the modified Richard Abbott model for tests 1 and 2 (test reference E9 and E10). They show good agreement with the experimental curves, as seen in Figs. 12 and 13.

Figs. 12 and 13 compare the values of the energy dissipated in each cycle and the strength values for the two tests. The error is quite insignificant for the cycles where the values of energy dissipated and strength are high. The energy dissipated and the strength of the joints demonstrate the good cyclic performance for these composite joint typologies.

The internal joints 3 and 4 (test reference E11 and E12) presented high ductility with similar response for hogging and sagging moments. The strength degradation was low, also because the maximum amplitude of deformation was not very high. The numerical curve shows a good agreement with the experimental results, as can be seen in Fig. 14. The conclusions in terms of energy dissipated and strength values are the same as for the previous tests. Moreover, these two tests presented a more stable 


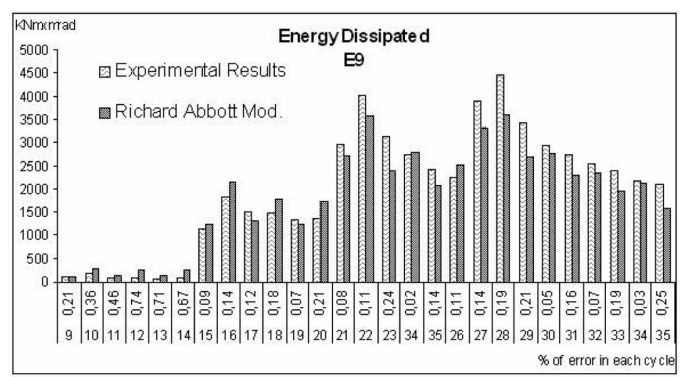

a) E9

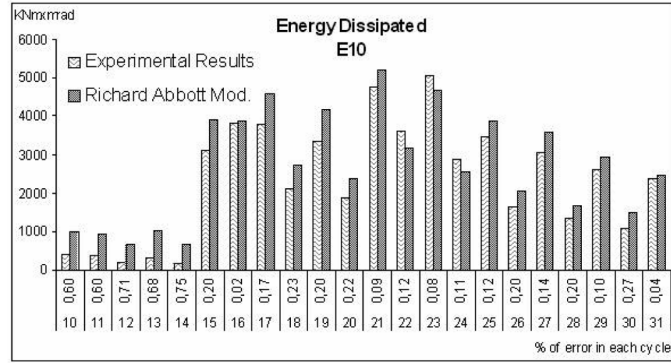

b) E10

Fig. 12 Energy dissipated in each cycle for joints 1 and 2

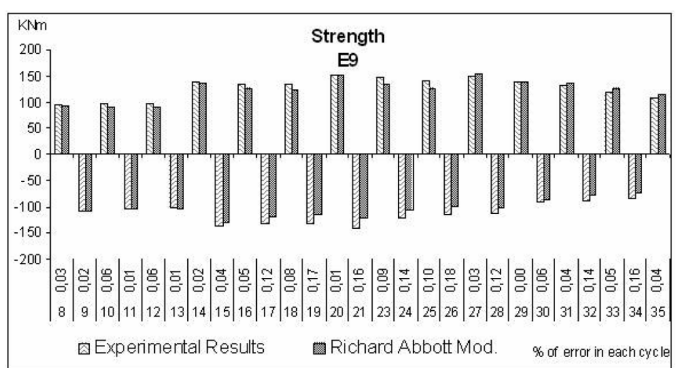

a) E9

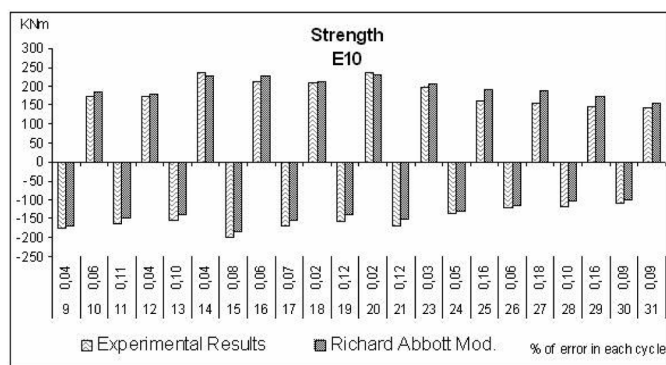

b) $\mathrm{E} 10$

Fig. 13 Strength reached in each cycle for joints 1 and 2
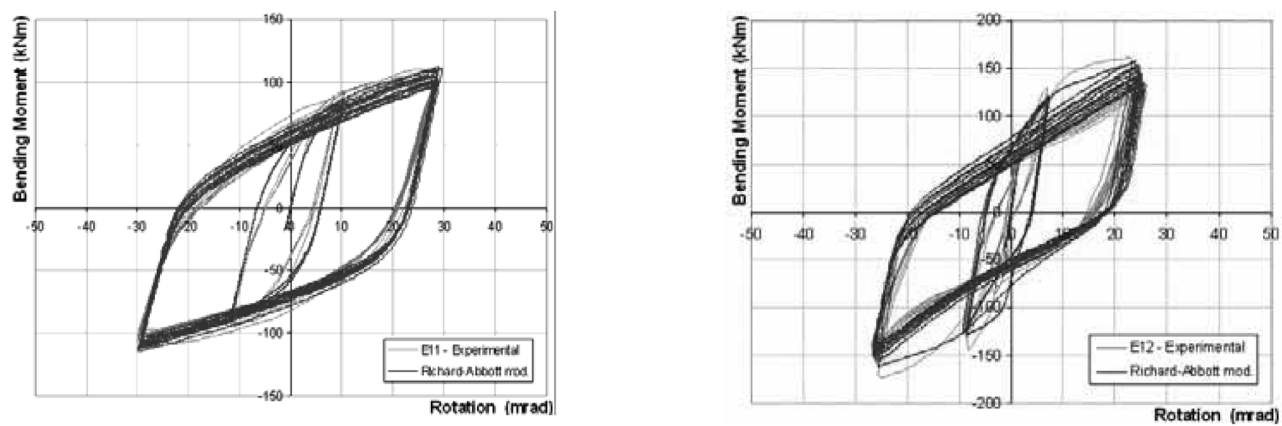

Fig. 14 Hysteretic curves for joints 3 and 4

hysteretic behaviour.

Figs. 15 and 16 illustrate the good agreement between experimental and numerical results in terms of energy dissipation and strength.

\subsubsection{End-plate joints 5 to 7}

The cyclic loading strategy applied to joints 5 to 7 is illustrated in Fig. 17, as well as the application of the Richard-Abbott model to the composite joints tested by Dubina et al. (2002). The maxima total joint rotations reached were $40 \mathrm{mrad}, 33 \mathrm{mrad}$ and $40 \mathrm{mrad}$, respectively, thus matching the Eurocode 8 


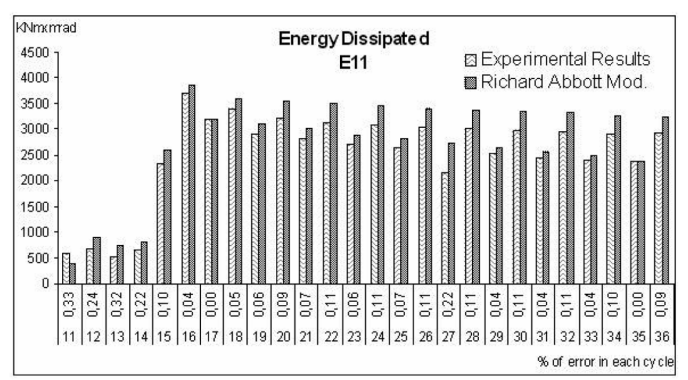

a) E11

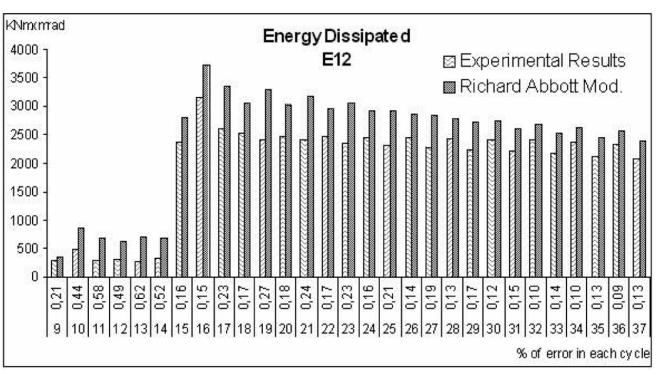

b) E12

Fig. 15 Energy dissipated in each cycle for joints 3 and 4

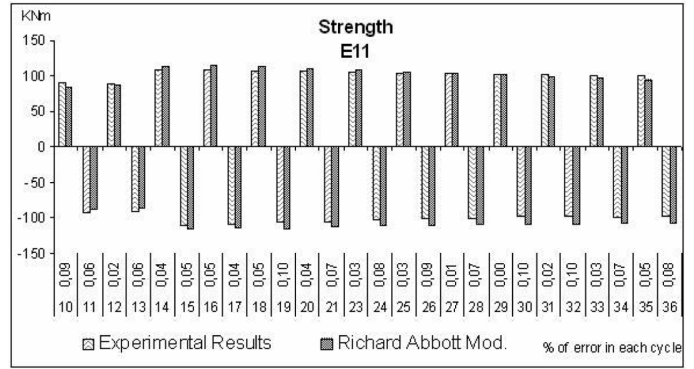

a) E11

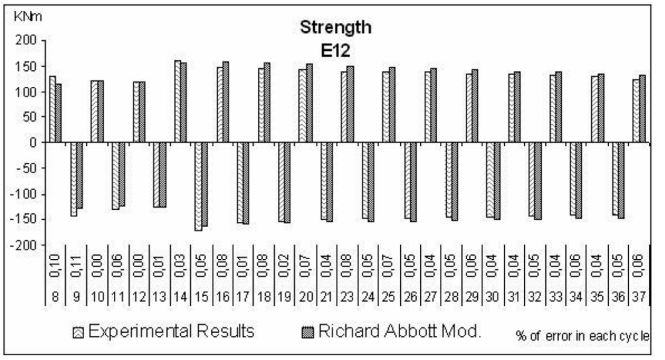

b) E12

Fig. 16 Strength reached in each cycle for joints 3 and 4
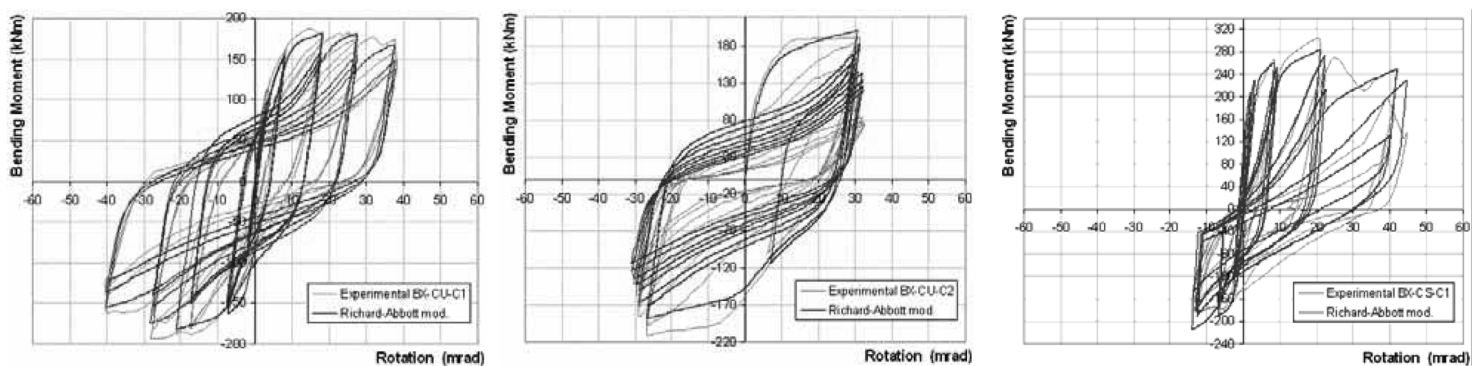

Fig. 17 Hysteretic curves for joints 5, 6 and 7

ductility requirements for dissipative joints.

The first two joints (joints 5 and 6 ) are structurally identical, but subjected to different cyclic loading procedures. For test 5 , the ECCS procedure was adopted, while for test 6 a constant amplitude loading procedure was used. While joints 5 and 6 are steel joints, joint 7 is composite with the addition of a composite slab. For this test, the load strategy is asymmetrical, as can be seen in Fig. 17. For positive bending moments the deformation reached $40 \mathrm{mrad}$ and for negative bending moments the deformation reached only $15 \mathrm{mrad}$.

Globally, for all three tests, the model is able to accurately reproduce the experimental results, as can be seen in Figs. 18, 19 in terms of energy dissipation and strength. 


\subsubsection{End-plate joints 8 to 9}

In the tests performed by Liew et al. (2004), the mode failure for joint 8 was excessive panel zone shear deformation and concrete crushing. The spalling of the white wash in the panel zone indicates extensive yielding of the column web. Since joint 9 was a bottom extended end plate, the tensile resistance of the bottom bolts was increased because of the additional bolt row and thus the main effect was an increase of the positive moment resistance. The failure modes observed included tension cracking of the column

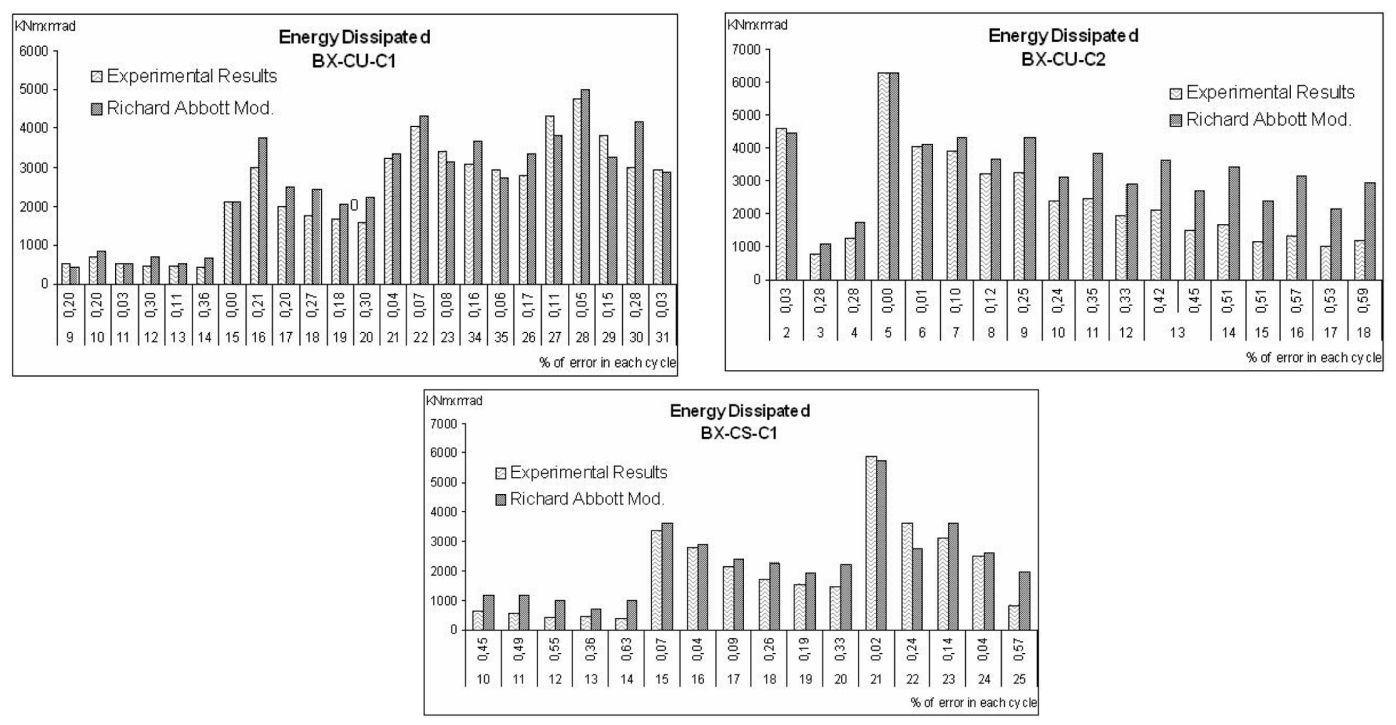

Fig. 18 Energy dissipated in each cycle for joints 5, 6 and 7

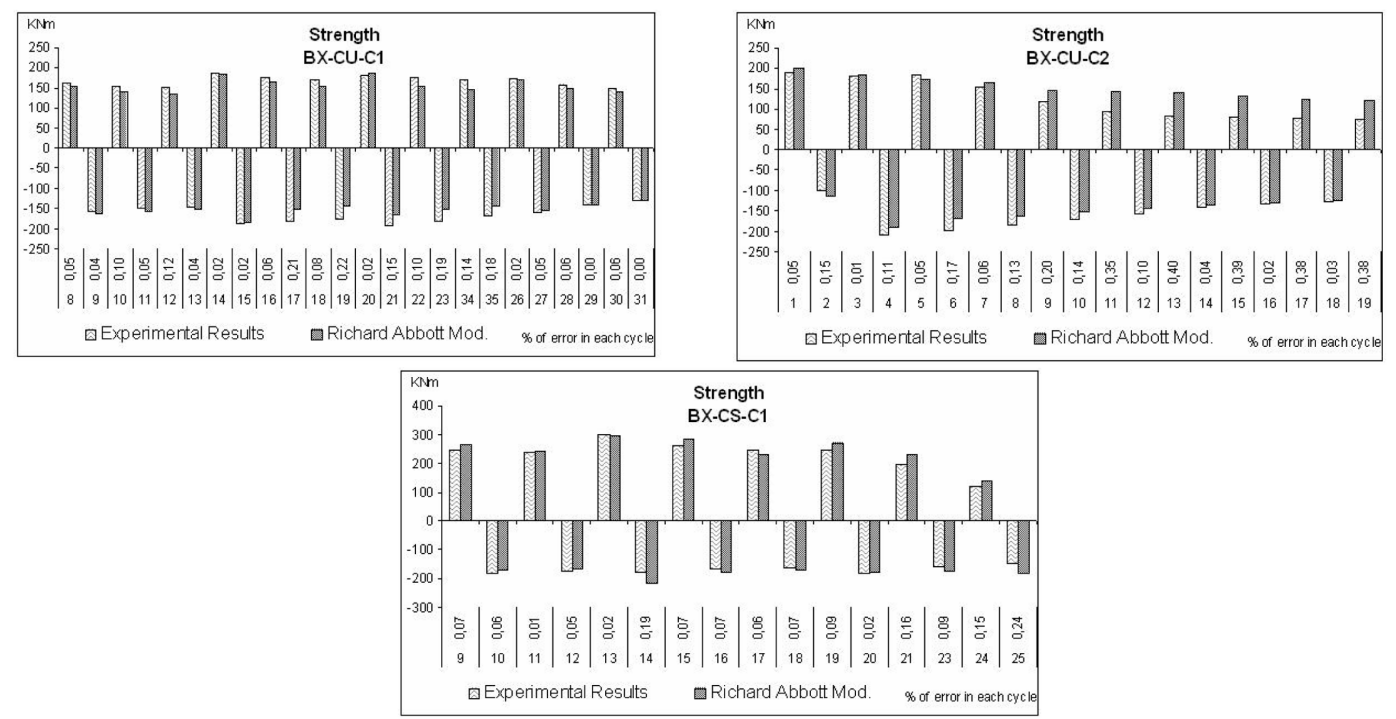

Fig. 19 Strength reached in each cycle for joints 5, 6 and 7 
web, concrete crushing, end plate bending, yielding of bolt and column web panel in shear.

The cyclic loading strategy applied to joints 8 to 9 led to the hysteretic curves illustrated in Fig. 20. The numerical model is able to reproduce adequately the experimental results. The maxima total joint rotations reached were $45 \mathrm{mrad}$ and $50 \mathrm{mrad}$, respectively, thus matching the Eurocode 8 ductility requirements for dissipative joints. For both joints the ECCS load strategy was followed. The deformation reached was high, leading to high values of energy dissipated. The hysteretic behaviour of joint 9 is more symmetrical than the other, due to the bottom extended end-plate.

Figs. 21,22 illustrate the good agreement between experimental and numerical results in terms of energy dissipation and strength.

\subsection{Proposal of hysteretic model parameters for composite end-plate beam-to-column joints}

Tables 6 and 7 summarize the results, for all parameters and for the nine tests.

Examination of the variation of the non-dimensional properties for the nine tests reveals that, except for tests 3 and 4 that present some deviations from the remaining tests (because they were only subjected to moderate rotations and did not reach collapse), the structural properties for strength and stiffness were fairly constant. These values can be seen in the last column of Tables 6 and 7. For the calibration parameters, it was not possible to find a clear tendency. This results from the small number of tests that are used and the variation of joint characteristics. Thus, for these parameters, a range of values is presented that covers all tested joints.
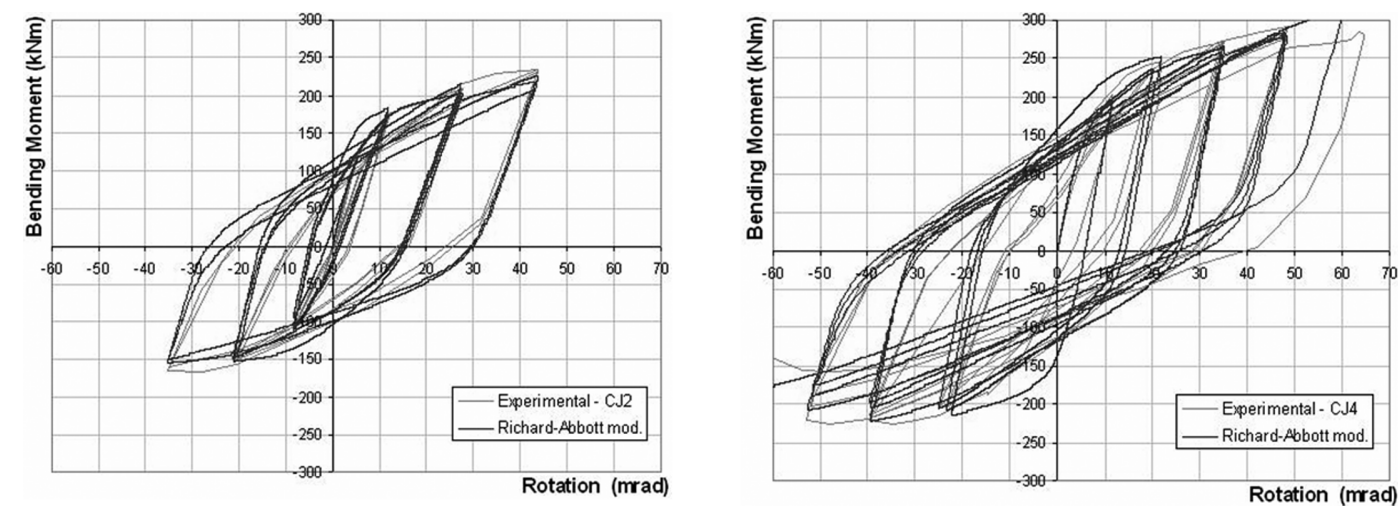

Fig. 20 Hysteretic curves for joints 8 and 9
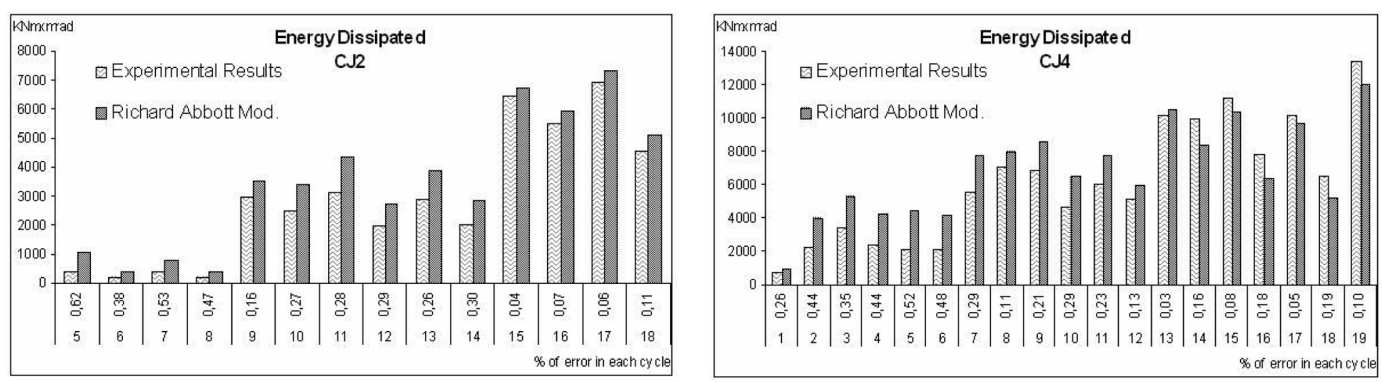

Fig. 21 Energy dissipated in each cycle for joints 8 and 9 

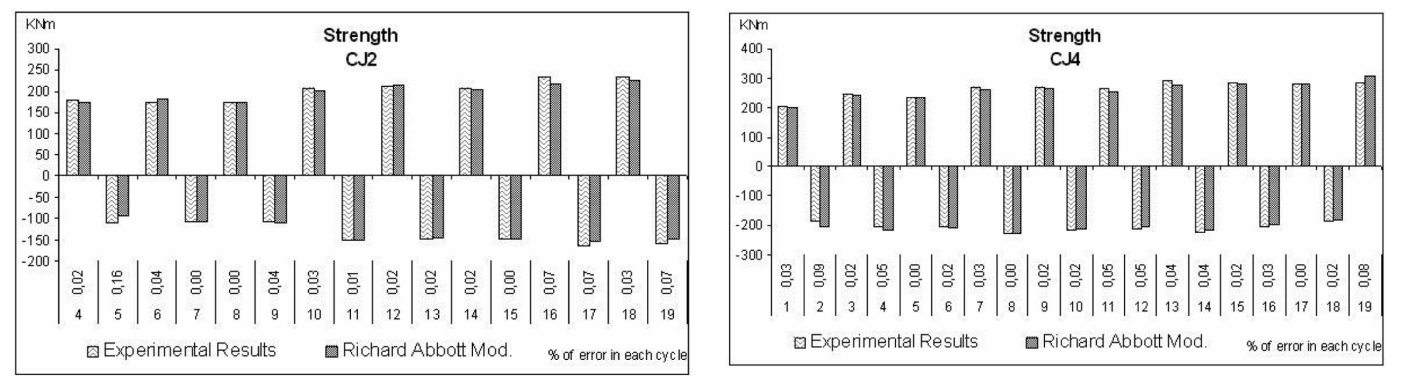

Fig. 22 Strength reached in each cycle for joints 8 and 9

Table 6 Joint parameters for all tests for the ascending branches

\begin{tabular}{|c|c|c|c|c|c|c|c|c|c|}
\hline Test $\mathrm{N}^{\mathrm{o}}$ & 1 & 2 & 3 & 4 & $5 / 6$ & 7 & 8 & $9 * *$ & Ref. Value \\
\hline $\mathbf{K}_{\mathbf{a}} \mathrm{KNm} / \mathrm{rad}$ & 24570 & 36950 & 16500 & 34400 & 36870 & 27648 & 32697 & 102500 & $\mathbf{K}_{\mathbf{y}}^{+}$ \\
\hline $\mathbf{M}_{\mathbf{a}} \mathrm{KNm}$ & 130 & 200 & 85 & 117 & 170 & 170 & 210 & 240 & $1.2 \times \mathrm{M}_{\mathrm{y}}^{+}$ \\
\hline $\mathbf{K}_{\mathbf{p a}} \mathrm{KNm} / \mathrm{rad}$ & 600 & 1025 & 825 & 1700 & 1100 & 1000 & 1300 & 3000 & $0.03 \times \mathbf{K}^{+} \mathbf{y}$ \\
\hline $\mathbf{n}_{\mathrm{a}}$ & 2 & 2 & 2 & 2 & 2 & 2 & 2 & 2 & 2 \\
\hline $\mathbf{K}_{\text {ap }} \mathrm{KNm} / \mathrm{rad}$ & 24570 & 36950 & 16500 & 34400 & 36870 & 27648 & 32697 & 102500 & $\mathbf{K}_{\mathbf{y}}^{+}$ \\
\hline $\mathbf{M}_{\text {ap }} \mathrm{KNm}$ & 70 & 140 & 40 & 60 & 100 & 100 & 120 & $1 * *$ & $0.65 \times$ Ma \\
\hline $\mathbf{K}_{\text {pap }} \mathrm{KNm} / \mathrm{rad}$ & 600 & 1025 & 825 & 1700 & 1100 & 1000 & 1300 & 3000 & $0.03 \times \mathbf{K}_{\mathbf{y}}^{+}$ \\
\hline $\mathbf{n}_{\text {ap }}$ & 1 & 1 & 1 & 1 & 1 & 1 & 1 & 1 & 1 \\
\hline $\mathbf{t}_{1 \mathrm{a}}$ & 15 & 10 & 6 & 10 & 15 & 15 & 15 & 15 & $6<\ldots<15$ \\
\hline$t_{2 a}$ & 0.5 & 0.5 & 0.15 & 0.15 & 0.5 & 0.1 & 0.1 & 0.2 & $0.15<\ldots<0.5$ \\
\hline $\mathrm{C}_{\mathrm{a}}$ & 1 & 1 & 1 & 1 & 1 & 1 & 1 & 1 & 1 \\
\hline $\mathbf{i}_{\mathbf{K a}}$ & 15 & 20 & 3 & 15 & 25 & 30 & 15 & 25 & $3<\ldots<25$ \\
\hline $\mathbf{i}_{\mathrm{Ma}}$ & 0.15 & 0.25 & 0.02 & 0.01 & 0.10 & 0 & 0 & 0.4 & $0.01<\ldots<0.25$ \\
\hline $\mathbf{H}_{\mathbf{a}}$ & 0.07 & 0.09 & 0.05 & 0.02 & 0.02 & 0.04 & 0.03 & 0.02 & $0.01<\ldots<0.09$ \\
\hline $\mathbf{E}_{\text {maxa }} \mathrm{rad}$ & 0.1 & 0.1 & 0.1 & 0.1 & 1 & 0.01 & 0.1 & 0.1 & 0.1 \\
\hline
\end{tabular}

According to Eurocode 8 (EN 1998-1, 2004), dissipative semi-rigid and/or partial strength connections are permitted, provided that all of the following requirements are verified:

a) the connections have a rotation capacity consistent with the global deformations;

b) members framing into the connections are demonstrated to be stable at the ultimate limit state (ULS);

c) the effect of connection deformation on global drift is taken into account using nonlinear static (pushover) global analysis or non-linear time history analysis.

Additionally, (i) the connection design should be such that the rotation capacity of the plastic hinge region $\theta_{\mathrm{p}}$ is not less than $35 \mathrm{mrad}$ for structures of high ductility class $(\mathrm{DCH})$ and $25 \mathrm{mrad}$ for structures of medium ductility class (DCM) with $q>2$. The rotation $\theta p$ is defined as (see Fig. 23)

$$
\theta_{\mathrm{p}}=\delta / 0,5 L
$$

where $\delta$ is the beam deflection at midspan and $L$ is the beam span and should not include the column elastic deformation; (ii) the rotation capacity of the plastic hinge region $\theta_{\mathrm{p}}$ should be ensured under cyclic loading without degradation of strength and stiffness greater than $20 \%$. (this requirement is valid 
Table 7 Joint parameters for all tests for the descending branches

\begin{tabular}{cccccccccc}
\hline \hline Test N & 1 & 2 & 3 & 4 & $5 / 6$ & 7 & 8 & $9^{* * *}$ & Ref. Value \\
\hline $\mathbf{K}_{\mathbf{d}} \mathrm{KNm} / \mathrm{rad}$ & 26810 & 40830 & 18830 & 36220 & 37920 & 16987 & 35118 & 75050 & $\mathrm{~K}_{\mathbf{y}}^{-}$ \\
\hline $\mathbf{M}_{\mathbf{d}} \mathrm{KNm}$ & 125 & 170 & 80 & 118 & 167 & 160 & 190 & 175 & $\mathbf{1 . 2} \times \mathbf{M}_{\mathbf{y}}^{-}$ \\
\hline $\mathbf{K}_{\mathbf{p d}} \mathrm{KNm} / \mathrm{rad}$ & 670 & 1020 & 940 & 1800 & 1140 & 425 & 1300 & 3250 & $\mathbf{0 . 0 3} \times \mathbf{K}_{\mathbf{y}}^{+}$ \\
\hline $\mathbf{n}_{\mathbf{d}}$ & 2 & 2 & 2 & 2 & 2 & 2 & 2 & 2 & $\mathbf{2}$ \\
\hline $\mathbf{K}_{\mathbf{d p}} \mathrm{KNm} / \mathrm{rad}$ & 26810 & 40830 & 18830 & 36220 & 37920 & 16987 & 35118 & 75050 & $\mathbf{K}_{\mathbf{y}}^{-}$ \\
\hline $\mathbf{M}_{\mathbf{d p}} \mathrm{KNm}$ & 60 & 75 & 60 & 60 & 110 & 90 & 100 & 110 & $\mathbf{0 . 6 5} \times \mathbf{M d}^{+}$ \\
\hline $\mathbf{K}_{\mathbf{p d p}} \mathrm{KNm} / \mathrm{rad}$ & 670 & 1020 & 940 & 1800 & 1140 & 425 & 1300 & 3250 & $\mathbf{0 . 0 3} \times \mathbf{K}_{\mathbf{y}}^{+}$ \\
\hline $\mathbf{n}_{\mathbf{d p}}$ & 1 & 1 & 1 & 1 & 1 & 1 & 1 & 1 & $\mathbf{1}$ \\
\hline $\mathbf{t}_{\mathbf{1 d}}$ & 6 & 15 & 5 & 20 & 20 & 15 & 15 & 20 & $5<\ldots<20$ \\
\hline $\mathbf{t}_{\mathbf{2 d}}$ & 0.2 & 0.5 & 0.15 & 0.15 & 0.2 & 0.1 & 0.1 & 0.5 & $0.15<\ldots<0.5$ \\
\hline $\mathbf{C}_{\mathbf{d}}$ & 1 & 1 & 1 & 1 & 1 & 1 & 1 & 1 & $\mathbf{1}$ \\
\hline $\mathbf{i}_{\mathbf{K d}}$ & 18 & 20 & 1 & 5 & 15 & 0 & 10 & 15 & $1<\ldots<20$ \\
\hline $\mathbf{i}_{\mathbf{M d}}$ & 0.10 & 0.11 & 0.01 & 0.01 & 0.10 & 0 & 0 & 0.01 & $0.01<\ldots<0.11$ \\
\hline $\mathbf{H}_{\mathbf{d}}$ & 0 & 0 & 0.02 & 0 & 0 & 0 & 0 & 0 & 0 \\
\hline $\mathbf{E}_{\mathbf{m a x d}} \mathrm{rad}$ & 0.1 & 0.1 & 0.1 & 0.1 & 0.1 & 0.1 & 0.1 & 0.1 & 0.1 \\
\hline
\end{tabular}

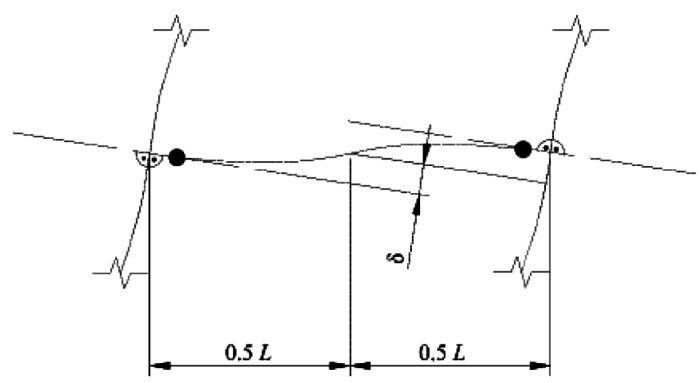

Fig. 23 Beam deflection for the calculation of $\theta p$

independently of the intended location of the dissipative zones); and (iii) the column web panel shear deformation should not contribute for more than $30 \%$ of the plastic rotation capability $\theta_{\mathrm{p}}$.

Table 8 shows that application of these criteria to joints 1 to 9 are approximately in line with the eurocode requirements. The column web panel contribution could not be verified because of lack of experimental data.

Table 8 Verification of Eurocode 8 requirements

\begin{tabular}{cccccccccc}
\hline \hline Test N & 1 & 2 & 3 & 4 & $5 / 6$ & 7 & 8 & 9 & Ref. Value \\
\hline Rotation capacity & 40 & 40 & $30^{*}$ & $25^{*}$ & $40 / 33$ & 40 & 45 & 50 & $\mathbf{2 5 ~ 3 5 ~ m r a d ~}$ \\
$* *$ Strength degradation: positive moment & 15 & 25 & 2 & 1 & 10 & 0 & 0 & 40 & $<\mathbf{2 0 \%}$ \\
$* *$ Strength degradation: negative moment & 10 & 11 & 1 & 1 & 10 & 0 & 0 & 10 & $<\mathbf{2 0 \%}$ \\
$* *$ Stiffness degradation: positive moment & 15 & 20 & 3 & 15 & 25 & 30 & 15 & 25 & $<\mathbf{2 0 \%}$ \\
$* *$ Stiffness degradation: negative moment & 18 & 20 & 1 & 5 & 15 & 0 & 10 & 15 & $<\mathbf{2 0 \%}$
\end{tabular}

* maximum rotation reached in test without joint failure

** number of cycles to reach $20 \%$ degradation 


\section{Conclusions}

The paper presents the numerical implementation of a hysteretic model able to simulate a generic cyclic steel-composite joint behaviour. It is incorporated in the structural analysis software SeismoStruct (Seismosoft 2007) as a joint element, thus allowing realistic non-linear static and dynamic structural analyses. The model was applied to nine experimental tests from three independent sources for composite joints, showing a very good agreement with the experimental results, even when using different cyclic loading strategies. Despite the small sample size, a clear trend was observed for the required model parameters for end-plate beam-to-column composite joints. A proposal of an interval range of design parameters for such joints was presented. Finally, these joints matched the eurocode requirements for dissipative semi-rigid, partial strength joints, showing that these joints may be safely used in seismic situations, although an extended validation should be sought.

\section{Acknowledgements}

Financial support from the Portuguese Ministry of Science, Technology and Higher Education (Ministério da Ciência, Tecnologia e Ensino Superior) under contract grants from PRODEP III (5.3), for Pedro Nogueiro, Foundation of Science and Technology through POCI/ECM/55783/2004 and FEDER through INTERREG-III-A (project RTCT-B-Z-/SP2.P18) is gratefully acknowledged. The assistance provided by Seismosoft, is also most appreciated (http://www.seismosoft.com). The supply of the data files from experimental tests by D. Dubina and R. Liew is warmly thanked.

\section{References}

Amadio, C., Benussi, F. and Noe, S. (1994), Behaviour of unbraced semi-rigid composite frames under seismic actions, In Behaviour of Steel Structures in Seismic Areas - STESSA'94, Edited by F. M. Mazzolani and V. Gioncu, E\& FN SPON, London, 535-546.

Bursi, O.S. and Ferrario, F. (2003), Computational Models for the Low-Cycle Fatigue Behaviour of Composite Members and Joints, Progress in Civil and Structural Engineering Computing, Edited by Topping, B. H. V., Saxe_Coburg Publications, Stirling, Scotland, 119-148.

Bursi, O.S., Lucchesi, D., Salvatore, W. (2003), "Partial-Strength Beam-to-Column Joints for High Ductile SteelConcrete Composite Frames," Proc. Ninth Int. Conf. on Civil and Structural Engineering Computing, Edited by Topping B. H. V., Civil-Comp Press, Stirling, Scotland.

Calado, L. (2003), Comportamento sísmico de ligações viga-coluna, Caracterização baseada na experimentação, IV Congresso de Construção Metálica e Mista, Lisboa, 4 e 5 de Dezembro, 645-656.

De Martino, A., Faella, C. and Mazzolani, F.M. (1984), "Simulation of Beam-to-Column Joint Behaviour under Cyclic Loads", Construzioni Metalliche, 6, 346-356.

Della Corte, G., De Matteis, G. and Landolfo, R. (2000), Influence of Connection Modelling on Seismic Response of Moment Resisting Steel Frames, Mazzolani FM, editor, Moment resistant connections of steel buildings frames in seismic areas, E. \& F.N. Spon, London.

Delphi 7 (2002), Borland Software Corporation.

Dubina, D., Ciutina, A.L. and Stratan, A. (2001). "Cyclic Tests of Double-Sided Beam-to Column Joints", J. Struct. Eng., 127(2), February.

Dubina, D., Ciutina, A.L. and Stratan, A. (2002). "Cyclic testes on bolted steel and composite double-sided beam-to-column joints", Steel Compos. Struct., 2(2), 147-160.

ECCS, Recommended Testing Procedure for Assessing the Behaviour of Structural Steel Elements Under Cyclic 
Loads, No. 45.

Emmett, A. Sumner and Thomas M. Murray (2002), "Behavior of Extended End-Plate Moment Connections Subjected to Cyclic Loading", J. Struct. Eng., 128(4).

EN 1994-1-1, Eurocode 4 (2004), Design of composite steel and concrete structures, Part 1.1: General rules and rules for buildings, European Committee for Normalization, Brussels.

EN 1998-1, Eurocode 8 (2004), Design of structures for earthquake resistance, Part 1: General rules, seismic actions and rules for buildings, European Committee for Normalization, Brussels.

Ermopoulos, J.C., Vayas, I., Petrovits, N.E., Sofianopoulos, D.S. and Spanos, C. (1995), Cyclic behaviour of composite beam-to-column bolted joints, In Steel Structures - Eurosteel '95, Edited by Kounadis, A. N., Balkera, A. A., Rotterdam, 205-210.

Filippou, F. C., Popov, E. P. and Bertero, V. V. (1983), "Effect of Bond deterioration on Hysteretic behaviour of reinforced concrete joints", Report No. UCB/EERC-83/19, Earthquake Engineering Research Center, University of California, Berkeley.

Lee, S.J. and Lu, L.W. (1989), “Cyclic Tests of Full-Scale Composite Joint Subassemblages", J. Struct. Eng., 115(8).

Leon, R.T. (1990), "Semi-rigid Composite Construction", J. Constr. Steel Res., 15, 99-120.

Leon, R.T., Hajjar, J.F. and Gustafsun, M.A. (1998), "Seismic Response of Composite Moment-Resisteng Connections, I: Performance", J. Struct. Eng., 124(8).

Leon, R.T., Hajjar, J.F. and Gustafsun, M.A. (1998), "Seismic Response of Composite Moment-Resisting Connections, II: Behaviour", J. Struct. Eng., 124(8).

Liew, J.Y.R., Teo, T.H. and Shanmugam, N.E. (2004), "Composite joints subject to reversal of loading, Part 1: experimental study", J. Constr. Steel Res., 60, 221-246.

Mazzolani, F.M. (1988), Mathematical model for semi-rigid joints under cyclic loads, R. Bjorhovde et al. (eds), Connections in Steel Structurs: Behaviour, Strength and Design, Elsevier Applied Science Publishers, London, $112-120$.

Nogueiro, P., Simões da Silva, L. and Bento, R. (2003), "Influence of joint slippage on the cyclic response of steel frames", Proc. of $9^{\text {th }}$ Int. Conf. on Civil and Structural Engineering Computing, Topping, B.H.V. (ed.), Civil-Comp Press, Stirling, United Kingdom, 66.

Nogueiro, P., Simões da Silva, L., Bento, R. and Simões, R. (2007), "Numerical implementation and calibration of a hysteretic model with pinching for the cyclic response of steel joints", Int. J. Adv. Steel Constr., 3(1), 128-153.

Pradhan, A.M. and Bouwkamp, J.G. (1994), Structural performance aspects on cyclic behaviour of the composite beam-column joints, Behaviour of Steel Structures in Seismic Areas - STESSA'94, Edited by F. M. Mazzolani and V. Gioncu, E\& FN SPON, London, 221-230.

Plumier, A. and Schleich, J.B. (1993), "Seismic Resistance of Steel and Composite Frame Structures", J. Constr. Steel Res., 27, 159-176.

Popov, E.P. and Bertero, V.V. (1973), "Cyclic loading of steel beams and connections", J. Struct. Div., ASCE, 99(6), 1189-1204.

Popov, E.P. and Pinkey, R.B. (1968), Cyclic loading of steel beams and connections subjected to inelastic strain reversals, Bull No. 3 (Nov.), American Iron And Steel Institute, Washington, D.C.

Ramberg, W. and Osgood, W.R. (1943), Description of stress-strain curves by three parameters, Monograph No. 4, Publicazione Italsider, Nuova Italsider, Genova.

Richard, R.M. and Abbott, B.J. (1975), "Versatile Elasto-Plastic Stress-Strain Formula", J. Eng. Mech., ASCE 101, EM4, 511-515.

SeismoStruct (2007), Computer program for static and dynamic nonlinear analysis of framed structures [online], Available from URL: http://www.seismosoft.com.

Simões da Silva, L., Simões, R. and Cruz, P. V. (2001), "Experimental behaviour of end-plate beam-to-column composite joints under monotonical loading", Eng. Struct., 23(11), 1383-1409.

Simões, R., Simões da Silva, L. and Cruz, P. (2001), "Cyclic behaviour of end-plate beam-to-column composite joints", Int. J. Steel Compos. Struct., 1(3), 355-376.

Sheikh, T.M., Deierlein, G.G., Yura, J.A. and Jirsa, J.O. (1989), "Beam-Column Moment Connections for Composite Frames, Part 1", J. Struct. Eng., 115(11).

$C C$ 